\title{
"humanidades
}

Revista Humanidades

ISSN: 2215-3934

humanidades@ucr.ac.cr

Universidad de Costa Rica

Costa Rica

\section{El origen del humanismo de la Bauhaus (1919-1933) en la cultura clásica griega: una mirada a través del alumnado femenino}

\author{
Vadillo Rodríguez, Marisa \\ El origen del humanismo de la Bauhaus (1919-1933) en la cultura clásica griega: una mirada a través del \\ alumnado femenino \\ Revista Humanidades, vol. 12, núm. 1, e49256, 2022 \\ Universidad de Costa Rica, Costa Rica \\ Disponible en: https://www.redalyc.org/articulo.oa?id=498068490009 \\ DOl: https://doi.org/10.15517/h.v12i1.49256
}

\section{(c) (1) @ $\Theta$}

Esta obra está bajo una Licencia Creative Commons Atribución-NoComercial-SinDerivar 3.0 Internacional. 
Desde el arte, la literatura y la comunicación

\title{
El origen del humanismo de la Bauhaus (1919-1933) en la cultura clásica griega: una mirada a través del alumnado femenino
}

\author{
The Origin of Bauhaus Humanism (1919-1933) in Classical Greek Culture: A Look Through the Female Student \\ Body \\ Marisa Vadillo Rodriguez \\ Universidad de Sevilla, Sevilla, España \\ marisavadillorodriguez@gmail.com \\ DOI: https://doi.org/10.15517/h.v12i1.49256 \\ Redalyc: https://www.redalyc.org/articulo.oa? \\ id $=498068490009$
}

https://orcid.org/0000-0003-0708-4596

Recepción: 13 Septiembre 2021

Aprobación: 26 Octubre 2021

\section{Resumen:}

El objetivo de esta investigación plantea una reflexión inédita que enlaza la pedagogía de la célebre Bauhaus (1919-1933) con ideales clásicos humanistas, cuyo origen esencial lo situamos en la Grecia clásica: physis, paideia, el templo, la armonía y la geometría. La investigación se ha basado en una metodología de estudio histórico y hermenéutico de carácter cualitativo, cuyas fuentes primarias son documentos originales conservados en el Bauhaus-Archiv de Berlín junto a bibliografía internacional consultada en The Warburg Institute de la Universidad de Londres, ya que gracias a esta se contextualizaron los datos previos del archivo alemán sobre la cultura griega clásica. Con el fin de visibilizar esta vinculación en su realidad más inexplorada, los referentes y figuras que se han usado en la investigación han sido acotados al alumnado femenino como sujetos menos conocidos en la producción artística general de la escuela. El artículo confirma y demuestra la tesis inicial sostenida: que la Bauhaus -posiblemente la última escuela humanista clásica en Europa- estaría más cercana a la cultura griega de lo que se ha considerado hasta ahora, este fenómeno, que permitió el salto a las vanguardias, estuvo presente en la producción de sus alumnas.

Palabras ClaVe: arte, diseño, geometría, griego, mujer artista.

\section{ABstract:}

The goal of this investigation is to explore a hitherto unconsidered connection that links the pedagogy of the celebrated Bauhaus (1919-1933) with classical humanist ideals, the essential origins of which take us back to classical Greece: physis, paideia, the temple, harmony and geometry. The investigation is based on a methodology involving historical and hermeneutic study of a qualitative nature, the primary sources for which are original documents held at the Bauhaus-Archiv in Berlin together with the international bibliography consulted at the Warburg Institute of the University of London, whereby the earlier information from the German archive is placed in the context of classical Greek culture. In order to highlight this connection in its least-explored guise, the personalities and figures used for the investigation are confined to the female students, owing to their being less wellknown participants in the general artistic output of the school. The article supports and corroborates the thesis as initially set out: that the Bauhaus - possibly the last classical humanist school in Europe - was closer to Greek culture than has previously been thought, and that this phenomenon, which enabled them to make the leap to their respective vanguards, was present in the output of its female students.

KEYWORDS: art, design, geometry, greek, women artists.

\section{INTRODUCCIÓN}

La escuela alemana Bauhaus (1919-1933) fue una escuela profundamente comprometida con el ser humano a través de su pedagogía y de las numerosas teorías que abordaron desde el arte. En apenas catorce años cambió la historia del arte, inventó el diseño moderno como categoría y lo estableció como disciplina; una argumentación defendida por autores de la talla de Satué en su célebre capítulo titulado "La Bauhaus impone el diseño gráfico como categoría disciplinar" (1999, pp. 147-167). Los exponentes de la Bauhaus revolucionaron así la arquitectura y establecieron -desde entonces- las bases pedagógicas de la mayoría de 
centros de arte o diseño creados con posterioridad en occidente. Son numerosos los autores que así lo han puesto de manifiesto a lo largo del último siglo en sus escritos, pero destaca, entre ellos, la fuerza de un clásico como Wingler, quien sentenció que la influencia determinante de la Bauhaus “está vinculada a su enseñanza elemental, que actualmente adoptan todas las academias e institutos de arte, desde luego en forma modificada, a tono con las exigencias de nuestro tiempo" (1975, p. 21).

Consideramos que, además de la naturaleza vanguardista que la consagró internacionalmente, fue más determinante aún una concepción esencial menos palpable que la convertiría, posiblemente, en la última academia clásica del sentir humanista en Europa. Un humanismo que asumieron, históricamente, a través de la creación del pensamiento, de la ciencia y de la tecnología propia de su modernidad, pero cuya raíz oculta creemos arraigada en un planteamiento antropocéntrico clásico general y en la cultura griega en particular. En cierto modo, la escuela se pronunció teórica, artística y socialmente como una manifestación de la inquietud humanista que había colocado al ser humano y la naturaleza, al orden de las cosas, en el centro de toda reflexión; un asunto que ya estaba muy presente en la antigüedad. Como diría Goethe, citado por Eckermann (2005): "...puestos a coger un modelo, debemos volver siempre a los antiguos griegos" ( p. 267).

Así, a pesar de la imagen de aparente frialdad formal que transmiten los modernos objetos que se crearon en ella, estos fueron resultado de una perfecta conjugación de razón y emoción, de vanguardia y clasicismo, de utilidad y estética, de una unidad de elementos cuyo origen creemos encontrar ya en la cultura griega a través de una serie de principios básicos, tanto conceptuales como formales: physis, paideia, areté, tecné, proporción, geometría, armonía, etcétera. Planteamos que, sin estos ingredientes fundamentales, la célebre Bauhaus no tendría, en ningún aspecto, la dimensión universal de la que disfruta. Su profesorado y su alumnado reordenaron el kosmos que les tocó vivir en Alemania tras el caos de la I Guerra Mundial, aplicando esta ordenación a la vida cotidiana, a través del diseño de objetos domésticos pensados para mejorar la sociedad en el ámbito estético, económico y espiritual. Piezas, cosas que, como bien sabemos, en cierto modo determinan lo que somos y nuestra forma de interactuar con el entorno, cuya forma y función nos definen como sociedad ya que son una manifestación de nuestra propia idealización del mundo. La célebre diseñadora Anni Albers (1899-1994), formada en la escuela, puso de manifiesto este fenómeno en uno de sus numerosos escritos en los que explicaba cómo el diseño debía ser anónimo y eterno, y lo hizo justamente apelando al ideal griego, comparando -en cierto modo- la esencia de las dos culturas, la clásica y la suya, a través de los modelos de producción, en una interesante reflexión sobre la pureza, la belleza y la utilidad de los objetos que una civilización crea:

Un antiguo jarrón griego, aunque no tenga ningún uso en la actualidad, nos sigue llenando de asombro. Lo aceptamos como
una manifestación de plenitud, de verdadera perfección. Un cubo actual, que hoy cumple en cierto modo la misma función
y es funcionalmente muy superior a la antigua vasija griega, nos avergonzaría y nos sonrojaría al ser nuestros estándares
culturales juzgados por aquella. Sentimos que está incompleto. Es cierto que algunos de nuestros productos técnicos actuales,
como el vidrio o la porcelana química, por ejemplo, o algunas obras de ingeniería, presentan, además de -o debido a-
su función claramente definida, una rara pureza de formas; son bellos. Pero de las muchas cosas que componen nuestro
utillaje actual, casi ninguna es pura en su forma, aunque quizás sí sea suficientemente útil. Por el contrario, los objetos más
artísticos, los productos de nuestra artesanía, suelen tener carencias tecnológicas y a menudo son, si acaso, sólo parcialmente
representativos de nuestra época (Albers, 1971, p. 2).

No olvidemos que el centro alemán consideró la condición espiritual que se manifiesta en la producción del objeto cotidiano. Paul Klee (1879-1940) lo manifestó meridianamente al determinar que "el conocimiento de lo que el objeto contiene dentro de sí lo hace crecer más allá de su apariencia superficial debido a la certeza de que la cosa es más de lo que su superficie revela" (Klee, citado en Whitford, 1992, p. 54). Esa cosa más 'que la superficie revela' (apariencia, tò phainoménon) entronca directamente con la importante concepción de physis griega. De los variados matices a lo largo de su uso en la antigüedad, consideramos que el planteamiento fundamental en su vinculación con la teoría y práctica de la moderna Bauhaus es la que defiende Tomás Calvo en su escrito "La noción de Physis en los orígenes de la filosofía griega". En este, Calvo (2000) realiza una 
completa investigación sobre cómo la filosofía se desarrolló en Grecia en torno a la noción de physis en los filósofos jonios de la escuela de Mileto. Una noción que pretendía explicar 'toda' la realidad como resultado de un proceso a partir de un origen o estado primero "en el que solamente habrían existido alguna o algunas sustancias primordiales" (p. 22).

Del mencionado artículo, nos interesan profundamente dos aspectos por su presencia en la condición fundamental que dio origen a la moderna Bauhaus:

Primero, la descripción de kosmos que Calvo hace, a través de Heráclito, en la vinculación de este concepto con la idea de orden; pero no cualquier orden sino el más adecuado, un orden que también se traduciría al orden social. En este sentido, ese ideal de kosmos es justamente el que se transfiere a través de los siglos a la utopía que dio origen a los productos que se diseñaron en la Bauhaus alemana y a su concepción de la sociedad de postguerra que les rodeó. Los artistas de la Bauhaus quisieron aplicar ese ideal para obtener, a partir de los principios propios del arte, objetos cotidianos que fueran el resultado del mejor orden posible de todos los elementos que intervenían en ellos: materias, formas, funciones, conceptos, implicaciones económicas, aspectos sociales, estéticos o plásticos. Un planteamiento que quedaría así unido a la idea de kosmos que Calvo sitúa en Anaximandro como orden de universo y orden en la polis. La Bauhaus, sin duda, necesitó y deseó ordenar la polis presente y futura a través de sus creaciones. Continuamente, sus protagonistas reclamaron ordenar el caos de postguerra europeo a través del arte y la vida. Entre los numerosos ejemplos de alumnado y profesorado que manifestaron por escrito sentirse en mitad del caos absoluto destaca Kandinsky (1866-1944) quien indicaba que, a ojos de un observador neutro, su época "puede señalarse también en una sola palabra: en contraposición al <> del siglo pasado, sería el caos" (2002, p. 92).

Segundo, la idea de physis como esa esencia, ese principio activo, imperceptible a través de lo aparente, que define de un modo oculto lo que realmente la cosa es, significado que aparece por primera vez en Homero (Calvo, 2000, pp. 32-33). Pero también entendida como "el proceso o génesis, el origen (sustrato) a partir del cual se inicia el proceso y el resultado final del mismo" (Calvo, 2000, p. 36). La physis de la Bauhaus definió su rica producción como resultado de una transformación, ya que sintetizó una serie de propiedades activas, universales, propias del arte para que fuesen principio de determinadas actividades o manifestaciones creativas que darían lugar a una serie de objetos que fueron mucho más allá de su apariencia y que cambiarían nuestro entorno para siempre. En este caso, en los artefactos que diseñaron los creadores y creadoras en la Bauhaus hay physis. Sus propuestas fueron el resultado de una génesis activa vinculada a la idea de orden, de kosmos, de geometría, armonía o proporción, cuya estructura podríamos considerar como physis de la creación artística, conectándola con el concepto clásico presocrático de physis. De este modo se superaría, quizás, esa oposición de contrarios que sitúa Calvo propia de la concepción platónica de physis frente al arte, los artefactos y la cultura.

A partir a este concepto esencial, el presente artículo -de naturaluza profundamente multidisciplinar y muy osado cronológicamente- tiene como objetivo plantear que el origen primero de los aspectos fundamentales en la pedagogía Bauhaus está ligado, consciente e intelectualmente, a algunos elementos claros de la cultura clásica griega, en su relación con la arquitectura, el saber y la naturaleza. A pesar de las evidentes diferencias históricas o sociales entre los dos fenómenos, establecemos aquí que la vinculación de la escuela alemana con la cultura clásica griega podría ser definitiva. Entre ambas realidades se dan una serie de nexos extremadamente profundos, como una necesidad muy potente de ordenar la realidad a través de varios principios formales ligados a la proporción, la geometría, la simplicidad o la armonía, tal y como hemos indicado, en una especie de evolución a partir de la concepción de physis original griega, metamorfoseada en cierto modo desde esa esencia inicial que contemplaba el saber griego en la creación natural a la esencia propia de la creación artística u objetual que aplicaría siglos después la Bauhaus a todos los objetos que diseñaron; unos objetos que querían construir sociedad, una sociedad en la que el rol del ser humano debía ser distinto, por lo que era imprescindible para ellos que sus piezas solucionaran unas nuevas demandas que permitieran la construcción de una nueva humanidad a través de un arte que generara objetos cotidianos llenos de espiritu. 
Ninguna otra escuela de arte (como comunidad) se ha comprometido tan ciegamente con su presente y con el futuro social colectivo, de ahí que podamos afirmar que ha sido la última escuela vinculada a los ideales humanísticos clásicos de transformación del ser humano a través de la educación y del arte. Aunque la idea de orden y kosmos podría estar implícita en otras manifestaciones culturales u otras escuelas artísticas, defendemos que no se dio con tal intensidad en ningún otro centro artístico o estilo histórico; ninguna escuela de arte ha tenido semejante compromiso ni impacto global. Esto se debería, especialmente, a dos motivos. Por un lado, a la situación histórica y socio-política tan singular de la Bauhaus (entre dos guerras mundiales, en Alemania), lo que llevó a una generación de jóvenes artistas a la imperiosa necesidad de 'ordenar' un futuro de manera urgente y profunda (para todos); en este contexto, no solo estaban creando piezas sino que esas piezas para ellos debían tener una implicación social, política, estructural y económica. En segundo lugar, se encuentra el original planteamiento pedagógico que asumieron: desde el arte, pero con una vinculación perpetua hacia la vida cotidiana, hacia la construcción de un nuevo modo de vivir y convivir. Una escuela que rechazó la formación de aquellos 'artistas al uso' anquilosados en producir piezas de arte únicas, exclusivas y elitistas. Contrario a lo anterior, los artistas de la Bauhaus crearon pensando en el ser humano, crearon para todos, su mayor éxito, en palabras de Naylor (1985), fue que "ellos significaron un cambio en el rol del artista y su relación tanto con su trabajo como con la sociedad” (p. 17).

Goethe, como se citó en Eckermann (2005), determinaba que "en la naturaleza hay una parte que nos es accesible y otra que no lo es" (p. 283). En la creación artística y el diseño también: ninguna obra de arte es solo lo que vemos de ella. Menos aún, las que se diseñaron en la Bauhaus. Precisamente, por estos dos aspectos señalados con anterioridad, pretendemos demostrar que la Bauhaus fue la última escuela humanista de Europa con un sentir profundamente clásico, reivindicando con esta investigación un punto de vista inédito de la escuela: su revolución no partió de la vanguardia sino de las herramientas humanísticas tradicionales que fueron las que usaron para construir dicha vanguardia. Ellos, como centro de formación artística, al rechazar la típica pedagogía de escuela de artesanía utilitarista o decorativa del momento fueron más allá de ese homo faber que construye (Flusser, 1999). Su compromiso, en pleno siglo XX, se insertó en una línea humanista que había surgido en la Grecia clásica y que se trasladaría históricamente hasta ellos a través de autores -entre otros muchos- como Leonardo da Vinci (1452-1519) por su visión del arte, de la observación, de la experiencia, de los sentidos aplicados al conocimiento para el diseño civil y lo social; de Martín Lutero (1483-1546) en su compromiso con un humanismo más democrático que implicaba la educación de más sectores sociales, o bien, a través de Giambattista Vico (1668-1744) por su planteamiento conocido como 'verum factum'. El concepto de verdad de este último estaba ligado a la idea del hacer, a la idea de la producción humana, una relación que se ha considerado, en ocasiones, precursora teórica del constructivismo artístico.

Queremos hacer explícito, además, el porqué de la mirada que proponemos a través de las creaciones de las alumnas. Las obras que ilustran esta investigación se limitan a piezas producidas por el alumnado femenino, quienes se formaron como artistas y diseñadoras al igual que el resto de sus compañeros. Ellas actualmente son reconocidas como figuras internacionales de prestigio cuya producción fue imprescindible para la supervivencia de la escuela y para el éxito de sus célebres productos. Nuestra intención es poner en valor que la figura de la mujer, en general, estuvo presente por igual tanto en aquella revolución artística como también en los pilares humanistas de aquel centro. Esta decisión con respecto al campo de estudio se toma por varios motivos: es fundamental este compromiso para normalizar la producción femenina en la historia del arte, permitiendo así un conocimiento más justo y exacto de la realidad histórica. Creemos fundamental poner especial énfasis en aquellos aspectos o temas tan inmensamente publicados como la Bauhaus, pero cuyas investigaciones no las tuvieron en cuenta a ellas hasta finales del siglo XX, a pesar de la calidad de sus propuestas. A ello se une que, gran parte de la docencia teórica de la escuela en materia de forma, composición y geometría se impartió, justamente, en el Taller de Tejido (ocupado exclusivamente por alumnado femenino). Como veremos, las teorías de maestros como Paul Klee o Kadinsky fueron imprescindibles en este taller. Un ejemplo de esta influencia lo tenemos en los manuscritos que dejó Lena 
Meyer-Bergner (1906-1981): "En todos estos trabajos nos sirvieron de mucho las conferencias del prof. Paul Klee. Nada influyó tanto en mi trabajo posterior como estas conferencias sobre la plasmación de la superficie" (Meyer-Bergner, s. f., Inv. No I 15590). Apoyamos así con esta propuesta el acercamiento al humanismo a través de una mirada que contempla la producción de la Bauhaus focalizada hacia nuevas líneas de investigación que han surgido en los últimos años en torno al análisis de una historiografía más inclusiva en la que el campo de análisis es más completo, sin obviar ninguna parte por una cuestión de género, sacando a la luz, precisamente, los aspectos y producciones menos conocidas, avanzando en la línea más inédita del conocimiento que supone la célebre escuela alemana, no con un una intención de sesgo sino justamente de enriquecimiento ${ }^{1}$ del objetivo principal del artículo que es mostrar la profunda presencia humanista de una escuela que, habitualmente, se ha vinculado a la vanguardia más rompedora. Si bien hubo una ruptura de moldes, este acto lo hicieron con herramientas clásicas que ya encontramos -como veremos- en la esencia de la cultura griega.

\section{LOS IDEALES DE LA CULTURA GRIEGA Y EL IDEARIO DE LA BAUHAUS: PAIDEIA, ARETÉ, TECNÉ}

Las coincidencias para establecer la esencia de la Bauhaus en el humanismo y en su origen griego no se limitan solo a aspectos formales. García determina dos perspectivas fundamentales del pensamiento científico en la Grecia clásica, señalando dos saberes que nos interesarán por su afinidad con la metodología pedagógica que se desarrolló en la escuela alemana:

El primero, el de los saberes, ligado al discurso de la ciudad, intenta comprender y dominar el ambiente natural mediante el encuentro dialéctico de un $<>$ (definido por un modo de acceso al conocimiento basado en la revelación de la verdad que es una, esférica y cerrada) y el $<>$ (definido por un modo de acceso al conocimiento que es resultado del esfuerzo, de la investigación, para descubrir una verdad que es múltiple y opinable, que no es completa ni acabada, sino perfectible y ampliable) (García, 1991, p. 108).

En cierto modo, en la Bauhaus permaneció constante el interés por relacionar estos dos saberes a lo largo de los periodos de las tres sedes en las que se desarrolló como escuela artística. En los primeros años, su misceláneo profesorado se dividía para cada asignatura en un 'Maestro de forma' y un 'Maestro de taller'. Con esta distinción pedagógica se establecía ya ese primer saber, presentado por García, ligado al saber del templo (ideal, cognoscitivo y con pretensión de verdad) con marcado énfasis dogmático, religioso y espiritual. Así, vemos cómo los distintos docentes que ejercieron -artistas como Kandinsky, Klee, Gertrud Grunow (1870-1944), Gunta Stölzl (1897-1983), Moholy-Nagy (1895-1946) o Gropius (1883-1969), entre otrostenían una serie de teorías muy concretas sobre el arte plástico, la arquitectura o la forma. Este saber se situaría frente a un saber del ágora (práctico, dialogante, progresivo y perfectible) ligado a la democracia ciudadana que mejoraría la vida diaria de los atenienses y que, en el caso de la Bauhaus, se estableció en numerosas reflexiones o discusiones entre la comunidad que la conformaba. Unos saberes que, a pesar de las diferencias que les separaban, se unificaron en la geometría, la funcionalidad, la simplicidad formal o en la trinidad cuadrado/rojo, circunferencia/azul y triángulo/amarillo que todos adoptaron como mandamientos. Cada maestro aportaba su saber, su dogma, resultado de sus particulares teorías: los saberes del templo Bauhaus.

En este sentido, es determinante el relato de una de las alumnas de Kandinsky, Ursula Schuh (1908-1993), quien llegó a la Bauhaus en 1931 para estudiar pintura con él. Al describir su primera impresión cuando entró en la clase del maestro, Schuh recordaba la profunda huella con la que fue marcada, al percibir cómo influía en el alumnado la metodología del profesor:

$\mathrm{Su}$ arte, sus experimentos artísticos simbolizaron exactamente el espíritu de su generación. Amabas romper con las viejas convenciones, pero también la precisión en la determinación y la formulación de nuevas opiniones, en cualquier campo, en cualquier clase de manifestación artística. Una amaba la abstracción, sentimiento <> (Schuh, 1970, p. 162). 
Por otro lado, también se fomentaba en la escuela el 'saber del ágora' al que apelaba la cultura griega, ya que su pedagogía, original, estaba muy ligada al intercambio de ideas. Era un centro internacional con un equilibrio inicial entre alumnas y alumnos, en el que la calidad generalizada del alumnado se debió principalmente a esa actitud de ágora, de intercambio y experimentación, que llevaría a la Bauhaus a exigirles, como explicaría décadas más tarde la célebre diseñadora Margarete Leischner (1907-1970), a "no conformarse jamás con la primera solución” (1968, p. 1048). Ejercieron en sus creaciones ese ideal griego del mejor orden posible.

Así, a través de este 'saber del ágora', de la puesta en común, del debate, se replicaría otra esencia de la cultura clásica griega imprescindible en la visión social de la escuela alemana: la paideia, un concepto que en la actualidad abarcaría aspectos modernos como 'civilización', 'cultura', 'tradición', 'literatura' o 'educación'. De hecho, el término clásico griego de paideia resumió el deseo por construir un ser humano ideal educado en la excelencia, un ser social al servicio de valores elevados, casi heroicos, que estaría marcado por la virtud, la areté. Esta última palabra concentraría todo el ideal educador del periodo griego, de la excelencia humana. Un ideal que tomó forma en el poema homérico con el poeta como el gran educador de una cultura griega primitiva. Jaeger explica que, a través de la poesía (no olvidemos que es precisamente una forma artística donde se vinculan arte y educación), Homero transmitió ese ideal de virtud humana: "El arte tiene un poder ilimitado de conversión espiritual. Es lo que los griegos denominaban psicagogia. Sólo él posee, al mismo tiempo, la validez universal y la plenitud inmediata y vivaz que constituyen las condiciones más importantes de la acción educadora" (Jaeger, 1957, p. 49).

Un planteamiento que, evolucionado, fue imprescindible en la educación que propuso la Bauhaus. En el ámbito más griego de la escuela se estableció el cultivo de lo espiritual a través de una pedagogía que determinaba como prioridad la excelencia de sus diseños, vinculada a un orden ideal social y universal que estaba sustentado por una visión ética de sus creaciones. Un ideario que desembocó en un potente y original compromiso económico y político con su época. Eran estudiantes, pero también ciudadanos/as claves de su comunidad, comprometidos con la realidad que les tocó vivir, fuese cual fuera esta.

Un ejemplo drástico de esta determinación del profesorado por educar a su alumnado en el compromiso social, en el ideal que implica la paidea, lo tenemos en la artista y alumna Friedl Dicker (1898-1944). De ella, diría el propio Gropius en un certificado que expidió el 29 de abril de 1931 (Bauhaus-Archiv Museum fur Gestaltung (BHA), 1931, Inv. No 1956):

La Srta. Dicker estudió en la Bauhaus desde junio de 1919 a septiembre de 1923. Destacó por su raro e inusual talento artístico; sus trabajos llamaban la atención constantemente. La naturaleza múltiple de su talento y su increíble energía hizo de ella una de los mejores estudiantes, tanto que el primer año empezó a enseñar a los noveles.

Dicker fue mucho más que una extraordinaria artista multidisciplinar. Ella intervino en la vida política de Alemania en un momento histórico peligroso, este uno de los motivos por los que fue deportada por el nazismo (con el número 548), finalizó sus días encerrada en el campo de concentración de Theresienstadt en el hogar femenino L410 donde, recuperando ese ideal asociado a la formación del ciudadano, esa 'ágora griega de la Bauhaus', decidió enseñar clandestinamente a dibujar a los niños y niñas que estaban encerrados en aquel lugar con sus madres. Pura paideia en pleno siglo XX, si bien insertada en el lugar de la Alemania nazi, totalitaria y contraria a los principios democráticos del ágora. Una clara manifestación del interés de la Bauhaus en educar a los individuos siempre a través del arte, desde los objetos que creaban con el fin de desarrollarles como ciudadanos ideales, sea cual fuera la circunstancia. Como indica Makarova: "las lecciones de arte, algo natural en todas las escuelas, eran un desafío al caos general y la armonía destruida de Theresiendstadt" (2001, p. 191), una manifestación comprometida fruto de una actitud de paideia, tal y como la entendían en Grecia. Un ideal que para Dicker, sin embargo, terminó bruscamente el 9 de octubre de 1944 en Auschwitz, pues al día siguiente de su llegada a este nuevo campo de concentración al que habían pedido el traslado, Dicker fue asesinada con la mayoría de mujeres y niñas que habían sido trasladadas junto a ella. 


\section{EL 'TEMPLO' COMO REFERENTE IDEAL EN EL PROYECTO EDUCATIVO. ARMONÍA Y PROPORCIÓN GRIEGA EN LA BAUHAUS: DE GERTRUD GRUNOW A OSKAR SCHLEMMER}

El segundo aspecto que podría estar vinculado conceptualmente a la physis griega original que consideramos fundamental en la esencia de la Bauhaus para entender su naturaleza profundamente humanista clásica sería, sin duda, el estudio y la experimentación de la proporción junto a la armonía; principios planteados como imprescindibles en el modelo educativo y pedagógico de la Bauhaus. Estos elementos activos, fundamentales para la pedagogía de la escuela alemana ya fueron celebrados, con mucha anterioridad, por la cultura griega. Nos recuerda Lino Cabezas (1995) que en la época de Pitágoras ya se conocían las tres proporciones fundamentales (geométrica, aritmética y armónica). Una idea que ya quedaba recogida en autores como Aristóteles (Arist. Metaf., I, 5, 985-986a: DK 58 B 4-5), siendo precisamente otro pensador griego, Pitágoras, a quien se le atribuye el descubrimiento de la proporción en la escala musical (Diógenes Laercio, VIII, 12) a través de cuerdas; un fenómeno fundamental, tal y como manifiesta Cabezas, ya que aquella sería "la clave que explicaba el secreto de la armonía en el universo" (1995, p. 252).

Estos principios activos clásicos estuvieron presentes en casi todos los aspectos plásticos, artísticos, conceptuales y arquitectónicos de la Grecia clásica. Como indica Burckhardt "el templo normal renuncia a toda diferencia en disposición, a toda combinación de lo diverso; quiere ser sólo la suma armónica de lo igual" (2010, p. 47). 'Seriación', así se diría en la Bauhaus, al basar sus objetos en repeticiones de prototipos, tanto en concepto (simplicidad, funcionalidad, economía, unidad) como en estética (colores y formas básicas, líneas y ángulos rectos). Estos principios tomados del arte y las matemáticas, desarrollados en plena vanguardia europea durante los inicios del siglo XX en el ámbito del diseño industrial y gráfico, funcionaron como se había entendido la physis griega: estos principios de creación son el proceso, el origen, a partir del cual se determinaría el resultado formal de los objetos o arquitecturas que plantearon y, por tanto, de la realidad que conformaban (ver Figura 1).

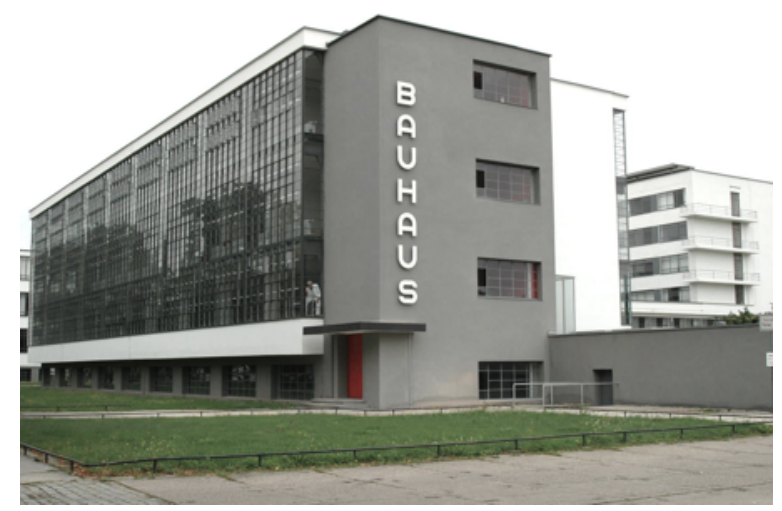

FIGURA 1.

Fotografía de la autora, 2005. Edificio de la escuela Bauhaus en Dessau, inaugurado el 4 de diciembre de 1926 y diseñado por el fundador y primer director de la escuela, Walter Gropius (1883-1969).

En la Bauhaus alemana, esos principios activos que los griegos habían aplicado al templo se encarnan en una escala menor, puesto que se vincularon a los objetos cotidianos y a espacios arquitectónicos que tienen relación con el ser humano. Así, tanto en los objetos y la vivienda ideal unifamiliar -que proponía la Bauhaus, véase Figura 2- como en el templo griego clásico, se expresa la esencia de un decálogo teórico e ideal afín, aplicado a la forma arquitectónica y objetual. Es evidente que los griegos construían y pensaban los templos desde fuera y con un fin sagrado al considerarlo 'vivienda de la divinidad', mientras que la Bauhaus planteó la arquitectura como un modelo de vida total desde dentro, un modelo profano que invadía todos los elementos internos, ajustando la vida real cotidiana a su ideario artístico y formal, desde el espacio habitado hasta la 
tetera o el tapiz con el que convivían. Muestra de ello son, por ejemplo, algunas de las arquitecturas que proyectaría años más tarde la alumna Annemarie Mauck (1906-1996), sobre todo, viviendas unifamiliares como las que ideó para Berlín-Zehlendorf (BHA, Inv. No 1997/26.44-53), planos conservados sin fecha exacta en el Bauhaus-Archiv.

No obstante, en ambas realidades arquitectónicas, el centro de toda relación era la ciudadanía, una nueva antropología que modificaba la relación del ser humano con lo que le rodea, anhela y le constituye. Así, el templo, aunque construido como espacio para albergar la imagen de culto, era una construcción en la que la ciudadanía interactuaba en las zonas exteriores.

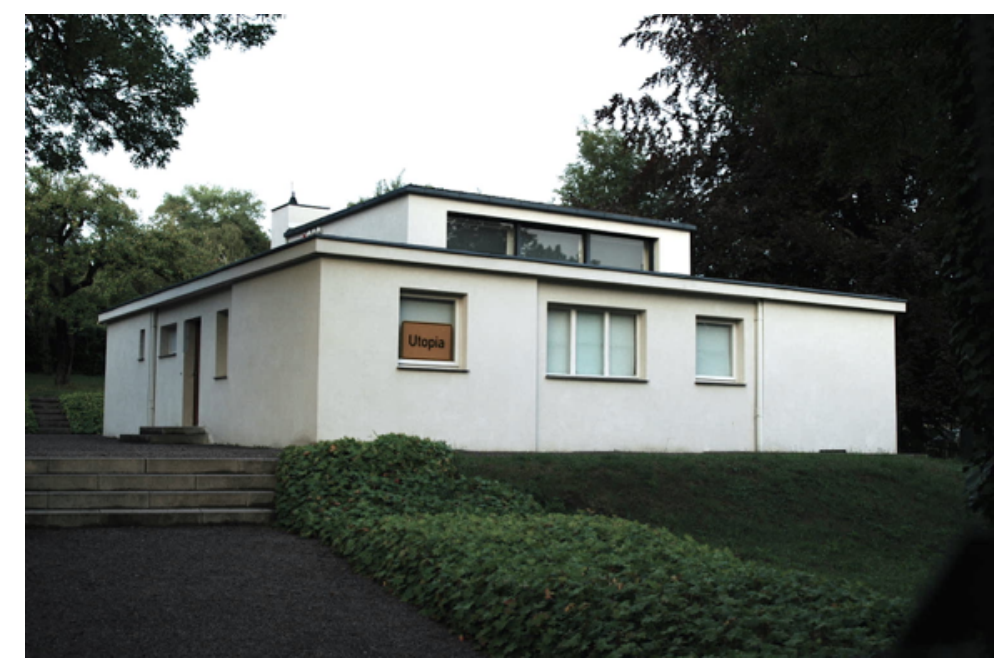

FIGURA 2.

Fotografía de la autora. Vivienda unifamiliar prototipo de la Bauhaus, conocida como Haus am Horn, Weimar, 1923.

Tanto las manifestaciones y las creaciones arquitectónicas griegas así como los objetos cotidianos de la vanguardista Bauhaus, aunque correspondan a épocas artísticas muy separadas en la historia, compartieron como principios irrenunciables el amor por el lenguaje geométrico o la armonía a través de formas esenciales y un rechazo radical del ornamento superfluo. La Bauhaus lo rehusaba, pero exigía que sus objetos estuvieran cargados de 'espíritu'. Rechazar el ornamento significaba, en cierto modo, querer romper con los estilos y la tradición histórica, dando respuesta a un planteamiento teórico que determinaría muchas de las inquietudes arquitectónicas o estéticas generales "desde la primera mitad del siglo XIX" (Kroll, 1987, p. 23). No olvidemos que el ornamento geométrico griego más elemental en su presentación como greca hace alusión a las formas elementales básicas del cuadrado o el círculo, tal y como destaca Silson (1994, pp. 29-31). Estas similitudes con el lenguaje formal de la escuela se extendieron al color, ya que nos consta que la estricta decoración cromática original en la forma arquitectónica griega se limitaba en la mayoría de los casos al azul, al rojo y al dorado. Una tradición que se vincula en línea directa con la potente trilogía plástica que determinaría la Bauhaus siglos después a través del azul, rojo y amarillo.

No nos ha de extrañar que ambos ideales estéticos -clásico griego y el de la Bauhaus- fueran el resultado de una concepción matemática del espacio y de su visión del ser humano en el universo. Idea ampliamente explicada por Calvo en una significativa y precisa conferencia en 2014 bajo el título Estética y matemáticas en elpensamiento griego:

La conexión entre belleza, arte y la naturaleza, juntamente con su origen matemático, es una idea que, sin duda alguna, entró en nuestra tradición occidental de la mano de la cultura griega. De modo que a los griegos se lo debemos. De una manera simple y rotunda podemos decir que tiene orígenes pitagóricos y que encuentra su máxima expresión filosófica y literaria en el Timeo de Platón (Manuscrito inédito cedido por el autor) ${ }^{2}$. 
El rol de la proporción, de la armonía, del orden -o la ausencia de este en el arte- ha sido una inquietud constante a lo largo de la historia de la creación. Es una propuesta casi innata de nuestra condición el dar una respuesta al caos establecido. El propio Platón defendía que "todo artífice que ejerce bien su oficio, que cumple bien su función, realiza en su obra un orden (kosmos), una armonía, una proporción de la cual resulta la perfección del conjunto" (Platón, Gorgias, 503d 504a). Es más, Edlund (1987) es definitivo en esta reflexión cuando se centra en cómo se elegían los espacios para erigir un templo: "para recrear, en términos de Eliade, el cosmos a partir del caos. A través de este fin el hombre logra los medios para vivir, para resolver y para expresar una conexión con lo divino" (p. 130).

También podríamos recordar a Ghyka (1927) cuando publicó Esthétique des proportions dans la nature et dans les arts, en especial, el capítulo V dedicado al crecimiento armonioso (pp. 165-219), una publicación que recoge la armonía de la naturaleza, pero también la que está presente en la creación artística. Otro ejemplo afín teórico muy original (llevado al ámbito estético) sería el del poeta Valéry, quien planteó estos temas con maestría en su obra dialéctica Eupalinos o el arquitecto (1923). Así, a través del personaje de Sócrates, el poeta expone que la construcción arquitectónica o creación son actos del espíritu, actos por los que se "construyen mundos perfectos en sí mismos, que a las veces se alejan del nuestro hasta lo inconcebible, y a las veces se acercan a él hasta coincidir en parte con lo real" (Valéry, 1982, p. 81).

Es probable que la Bauhaus fuera el primer espacio artístico educativo en el que el arte coincidió con lo real de un modo transversal y masivo, estableciendo a través de la proporción y armonía en el diseño de objetos cotidianos un mundo idealmente perfecto, quizás frente a la barbarie que les rodeaba. La escuela alemana, sin duda, experimentó cierto halo 'sagrado' y espiritual a través del arte de su tiempo, desarrollándolo en el ámbito de la vivienda unifamiliar y en sus objetos cotidianos, una experiencia en arquitectura que también exploró su alumnado femenino (Vadillo, 2013).

Un ejemplo de aplicación de estos ideales en torno a la proporción o la armonía, lo encontramos en el Curso Preliminar (Vorkurs) obligatorio (en casi todo el periodo de la escuela), tras el cual el Consejo de Maestros decidía quién sería aceptado y quién no. En este curso inicial, el objetivo era introducir al alumnado en un planteamiento global con respecto a la creación "explorando materiales, cuestionando el pensamiento convencional, pasando de un taller a otro antes de especializarse" (Kirkham y Weber, 2013, p. 614). Precisamente, era en este periodo cuando se asistía a la fascinante asignatura 'Teoría de la Armonía' que impartió la profesora Gertrud Grunow, entre 1919 y 1923 en Weimar. A Grunow se le reconocía, como docente, una gran intuición para detectar habilidades del alumnado. Como profesora profesional de música, se servía de un piano para explicar su singular teoría artística. Su compleja visión del sonido, de la forma humana en general como una forma viva relacionada con la sinestesia, le hizo abordar la creación desde un ámbito muy original al vincularlo con el movimiento, el color, la psicología, el estado de ánimo, la música y la geometría. Ella planteaba una visión sinestésica del organismo humano, reconocía la interrelación de los sentidos, no solo en la percepción con el exterior sino en la íntima conexión de unos sentidos con otros en nuestro interior, anticipándose así a planteamientos y teorías del cuerpo o la percepción tan interesantes como las de Merleau-Ponty (1908-1961). De este modo, aplicaba su teoría para ayudar al alumnado en su propia búsqueda del equilibrio armónico y para desarrollar sus capacidades artísticas innatas, unas capacidades que tenían que manifestarse a través de una visión multidisciplinar del ser humano.

En este sentido, Grunow desarrolló todo un orden, un kosmos, en una valiosísima tabla de equivalencias (Vadillo, 2016, p. 229) que vinculaba estos aspectos tomando como referente una estructura similar a la de un círculo cromático clásico, estableciendo de este modo el primer circuito sensible que percibiríamos. Esta propuesta de la asignatura de Armonía, que buscaba en el alumnado la proporción y el equilibrio, era muy interesante para ellos ya que les ayudaba a pensar, vincular y traducir unos aspectos de la plástica o del arte en otros que necesitarían para el diseño de objetos o la creación de espacio. Una transversalidad que convertía una parcela particular, de una disciplina artística, en un concepto global y humanístico del arte total. Por ejemplo, en su ordenación, la maestra determinaba que al número uno le correspondía el color blanco, que 
a su vez -si este fuese una nota musical- sería el sonido $d o$, un sonido que si tuviéramos que explicarlo en estado psicológico se traduciría en un 'alma fría'. Estas equivalencias entre numeración, color, notas musicales y alma finalizaban con aspectos más concretos para los estudiantes de la Bauhaus, quienes tenían al objeto como manifestación fundamental de su creación: los aspectos de la forma y el material.

Así, Grunow defendía que el 'uno = blanco = do = alma fría' sería formalmente una línea ondulada horizontal y le correspondería como material, además, el mármol. Un planteamiento muy coherente e interesante para esa búsqueda de equilibrio y de armonía, que vincula estos aspectos fundamentales de la concepción o creación del diseño de objetos. El material y la forma son dos aspectos que nos transmiten perceptiva y psicológicamente información, nos comunicamos a través de ellos. Para Grunow, ya en 1923, lo importante no era en sí el color o el sonido, sino 'la sensación', la fuerza viviente, sus leyes armónicas y su interrelación (Grunow, 1975, p. 88). Para la maestra, estas relaciones entre los sentidos manifestaban y determinaban la realidad con mayor acierto que si los aislábamos o los parcelábamos. No olvidemos que la propia Anni Albers (1971) defendió en sus escritos que "el diseñador es el coordinador de todas las fuerzas que afectan a su producto” (p. 62): esa es la fuerza viviente, la armonía, de la que Grunow nos hablaba. Como si fuera un pequeño demiurgo que, al coordinar, evidentemente, también ordena.

Esta inquietud por la armonía, por la proporción como concepto, no era exclusiva de esta asignatura. La proporción es geometría, pero también es ritmo, repetición, es tiempo. Así, estos principios abstractos que se habían establecido en la cultura griega con la búsqueda de un canon artístico (escultórico y arquitectónico) ideal se trasladarían, en cierto modo, al canon que proponía la Bauhaus. No solo por su código abstracto de círculo, cuadrado y triángulo como ordenación fundamental de todas las formas que producían, sino por los singulares cánones humanos que propusieron, tanto la mencionada Gertrud Grunow como el propio Oskar Schlemmer. Este último propuso en 1928 un canon antropométrico titulado El ser humano en su contexto, el cual no se basaba en la cabeza como medida de unidad tal y como había hecho la cultura clásica griega, sino que Schlemmer planteó un canon que iba mucho más allá; un canon cuya naturaleza quería ser igualmente universal, pero vinculando la forma humana con lo que le rodeaba, iba más allá de la geometría: "(...) la esfera de la cabeza y de los ojos / el triángulo de la nariz / la línea que une corazón y cerebro / la línea que une rostro con aquello que vemos (...)" (Schlemmer, citado en Kirchmann, 2000, p. 285).

Así, la proporción y armonía, fueron esencias humanistas que dieron sentido a toda la producción industrial de la Bauhaus siglos después. De la armonía del templo al canon humano que aplicó Grecia en su escultura clásica no hay más que un cambio de escala en cuanto a ideal. Es significativo señalar esa mirada al pasado clásico a través de la vanguardia artística en diseños como las marionetas que Ilse Fehling (1896-1982) realizó en la escuela (véase Figura 3), aquí se hace muy evidente pues el artista domina esa ley de frontalidad que ya aparece en la composición canónica griega de los kuroi durante los siglos VIII y VI a. C. La escultura griega se inició con un periodo geométrico, con geometrismo, con frontalidad, con rigidez, con armonía, con cierta inexpresividad que también estuvo presente en la producción volumétrica abstracta de la escuela alemana, en plena vanguardia artística e industrial, en pleno siglo XX. 


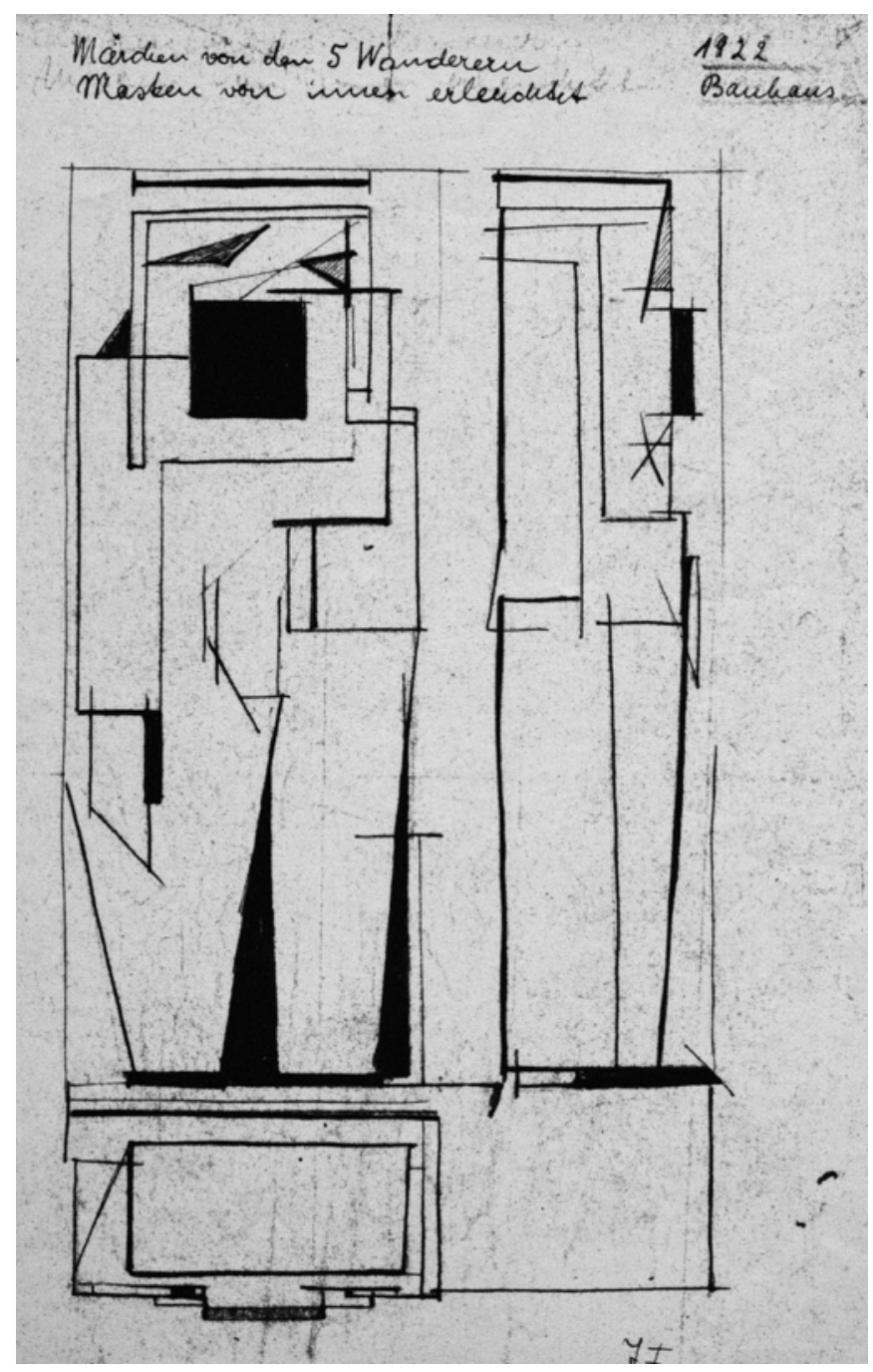

FIGURA 3.

Bauhaus-Archiv Berlin (BHA), Ilse Fehling, bocetos de marioneta

(planta abajo, alzado frontal a la izquierda y lateral a la derecha), 1922

De hecho, fue una máxima en la Bauhaus el entender la creación como resultado de una compleja concepción del ser humano donde la armonía tenía la función, a través del objeto creado, de transmitir los ideales de la escuela. Precisamente, Tut Schlemmer (1970, p. 159) definió por escrito los fundamentos de la Bauhaus en su relación con la creación escenográfica como una simbiosis en la que la expresión teatral aportaba un toque de humanismo a los principios de enseñanza presentes en su pedagogía:

Los elementos son espacio, forma, color, y luz: el espacio -su planimetría, su ley y su misterio-; la forma -de sus múltiples manifestaciones como superficie plana o esculpida-; el color -como fenómeno, su influencia recíproca, la armonía, disharmonía-; y la luz -la iluminación, la proyección, la transparencia y la profundidad deben ser medios indispensables para demostrar las leyes internas esenciales en función de la escena, lejos de tendencias naturalistas de la imitación-.

Por ello, es probable que la afinidad entre la máscara de mueca fija y simbólica presente en el teatro griego y la máscara abstracta del teatro vanguardista de la Bauhaus tampoco sea casual y estemos ante otro indicativo de la presencia de la raíz griega en la producción artística de esta moderna escuela. 


\section{LA GEOMETRÍA CLÁSICA COMO BASE CREATIVA Y PLÁSTICA DEL DISEÑO VANGUARDISTA EN LA BAUHAUS}

Valéry (2004) consideraba que la mente humana necesitaba reflexionar sobre la tensión que se crea entre el orden y el desorden (p. 50), una idea griega que le dio mucho repertorio a Nietzsche con la dialéctica entre lo apolíneo, racional, frío, reflexivo y lo dionisíaco oscuro, caótico, creativo; un eterno desafío de equilibrios formales y conceptuales que -por lo general- se resuelve a través de las matemáticas, de la proporción o del número. La Bauhaus transmitió la solución a este dilema a través del contenido estético con formas cotidianas simplificadas, seriadas, bellas, industriales y baratas, con el estudio de su superficie, de los planos, del lenguaje cromático, de la composición geométrica y la abstracción formal. Por ello, la Bauhaus fue, en esencia, una escuela constructora en la que un conocimiento resultó fundamental: la geometría. De hecho, Krimmel, como director de la exposición celebrada en 1986 bajo el título Symmetrie in Kunst, Natur und Wissenschaft, planteó en dos amplísimos volúmenes la presencia simétrica en el arte y su relación con la naturaleza y la ciencia a lo largo de muy diversas épocas, en un recorrido histórico que llegó hasta el mismo siglo XX, donde señaló a la Bauhaus al destacar algunas piezas como las realizadas por Oskar Schlemmer (Krimmel, 1986, p. 452).

Así, observamos una esencia humanista en la pedagogía de la escuela, un planteamiento que tendría su origen último en la cultura griega, donde la geometría se había contemplado tanto en el tratamiento estructural de la figura humana escultórica como en la decoración cerámica o en la medición arquitectónica.

La novedad histórica sería que, en la escuela alemana, el uso de estas figuras geométricas se vincularía a un lenguaje cultural propio de una época industrializada (véase Figura 4) y esto propició, como indican Lupton y Abbot, una mayor "conciencia de la función social del artista" (1993, p. 20). La geometría se volvió entonces política, economía, estética y sociedad, motivo por el que invadió toda la naturaleza formativa de esta famosa escuela. Eran estudiantes, pero también ciudadanos clave de su comunidad o de la sociedad que les tocó vivir. Un vínculo, el del compromiso humanista en la educación y su naturaleza política, que manifiesta meridianamente Nauert (1995), defendiendo una educación humanista desde la infancia:

\footnotetext{
Este énfasis en la educación como necesaria para el servicio político es especialmente importante porque demuestra que la educación humanista es práctica. Otra característica notable es su énfasis en el desarrollo de los talentos individuales, por lo que Vergerio señala que cada niño es único (p. 45).
}

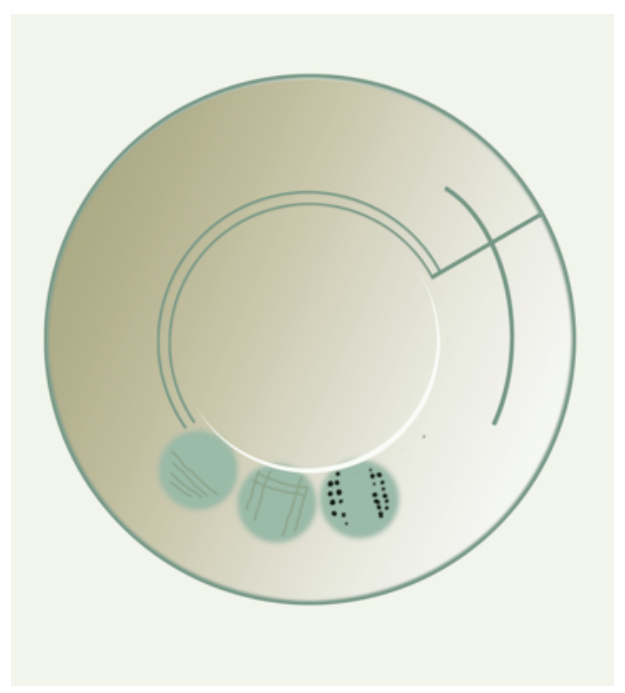

FIGURA 4 .

Recreación gráfica de cerámica diseñada por Grete Marks (1899-1990), formada en la Bauhaus. Ejemplo de decoración geométrica abstracta. 
Posiblemente, los profesores más centrados en el estudio de la forma y la geometría clásica fueron Paul Klee y Wassily Kandinsky. El primero desarrolló una asimilación de estos principios, que tradujo a un lenguaje universal de la forma, en aspectos geométricos abstractos y conceptuales: proceso que llevó a cabo creativamente tanto en el Curso Preliminar como en sus clases de Forma Libre 'freie gestaltung'. Sus programas se centraban en el estudio de la Forma Elemental 'elementaren Gestaltungslehre', una idea fuerza que presidió la pedagogía de sus cursos desde 1921 hasta 1931 y que consistía en el encuentro y abordaje de distintos aspectos de la creación a través de las formas elementales, contemplando desde la dimensión geométrica compositiva hasta la relación cósmica de la forma. De nuevo, la presencia de orden y kosmos griego presentes en la escuela. Una pedagogía formal que tuvo un impacto imprescindible en todas las alumnas del Taller de Tejido, lo que provocó que estos diseños textiles se incorporasen a la corriente de manifestaciones plásticas más vanguardistas de la década de 1920, motivo por el cual fueron expuestos en algunos de los museos más importantes de occidente como el MOMA, incluso, hoy en día estos diseños siguen atesorados en los centros artísticos de mayor prestigio.

Conservamos estas enseñanzas de Paul Klee a través de los apuntes originales de diversas alumnas, tales como Gertrud Arndt (1903-2000), Grit Kallin-Fischer (1897-1973), Helene Nonné-Schmidt (1891-1976), Lisbeth Birmann-Östreicher (1902-1989), Margarete Leischner (1907-1970), Otti Berger (1898-1944) o Gunta Stölzl. En ellos podemos apreciar el estudio de lo que el artista denominó como polifonía (polyphonie) de la forma plástica, un concepto tomado de la música. De este modo, los diseños textiles geométricos se convirtieron en 'objetos polifónicos' (véase Figura 5), vivos, en "tejedura de complejos” tal y como lo denominaba en sus apuntes Meyer-Bergner (s.f., Inv. No I 15590). En este manuscrito original, escrito en alemán y castellano, sin paginar, la autora defiende que -para ellas- los textiles cohabitaban en el espacio y funcionaban como elementos arquitectónicos, no como ornamentación, debido a que interactuaban creando espacio. Este principio formal estuvo especialmente presente en la estética conceptual de los productos realizados por las alumnas del Taller de Tejido. De este modo, abordaron la geometría tanto desde la teoría como en la práctica, ya que gracias a ella proyectaban las piezas por realizar a través de bocetos para los prototipos de tejidos. Creaciones, según Hervás y Heras (2015), en las que “dominaban la extensión del plano" (p. 281). 


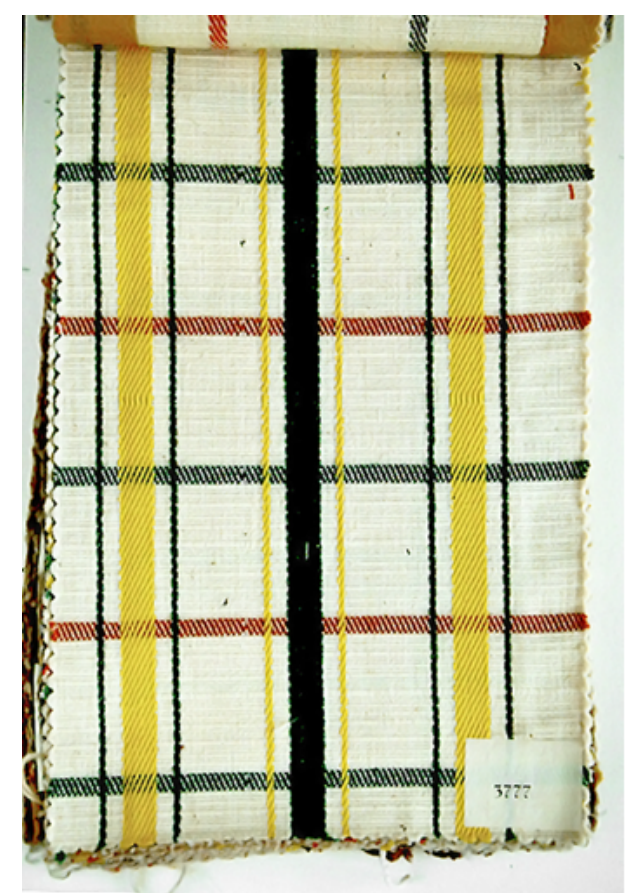

FIGURA 5.

Bauhaus-Archiv Berlin, Otti Berger, muestrario Gordijnstoffen D.P., modelo Carreaux, Inv. № 3777. Ejemplo de composición polifónica.

Kandinsky, por su parte, impartió Dibujo Analítico (Analytische Zeichnung). Pocos como él defendieron el lenguaje estructural como principio esencial de creación, un fenómeno que planteó también en su célebre escrito Punto y linea sobre plano. Basados en este lenguaje estructural impulsado por Kandinsky se conservan trabajos originales (véase Figura 6) realizados por alumnas como Katja Rose (1905-1994). Este contenido procedía de su asignatura Enseñanzas de la Forma y Color, donde el artista y docente desarrollaba esa pasión por la estructura geométrica que se manifestaba a través del análisis estructural del modelo en vivo presentado al natural, no para su mímesis sino para extraer su síntesis interna, su physis. De esta manera, fomentaba un estudio visual y conceptual de la estructura que sería imprescindible para la creación posterior que realizaba el alumnado, tanto de los objetos que diseñaban como de las composiciones en los célebres collages o en las fotografías de sus fotogramas abstractos, entre otros. Buscaban así el proceso que definió Torres (1952) al referirse al artista abstracto que deja ver el mundo real y "ve ese otro. Y acomoda su arte a esa geometría y medida" (p. 23). En creación plástica, esa estructura esencial, esa 'physis', es abstracta y geométrica. Un proceso que se comparte con la naturaleza, tal y como la entendía el propio Goethe y así lo manifiesta en su Metamorfosis de las plantas, una publicación en la que él plantea "descubrir cierta unidad simple entre la gran variedad vegetal, una planta primordial o arquetípica: una $<>$ (Urpflanze)" (Goethe, 2020, p. 17). El autor, en esta publicación, buscó un arquetipo que iría más allá de la visión u observación empírica, donde fenómenos naturales individuales podrían dar lugar a una ley interna de la naturaleza. No olvidemos que la representación en dibujo de la estructura como una construcción intelectual, a partir de la observación o como pensamiento, sería un medio para reinventar la realidad. Un fenómeno que parece innato al ser humano, tal y como señala Edgeston (1975): "la mente humana posee una capacidad innata para estructurar" (p. 157). 


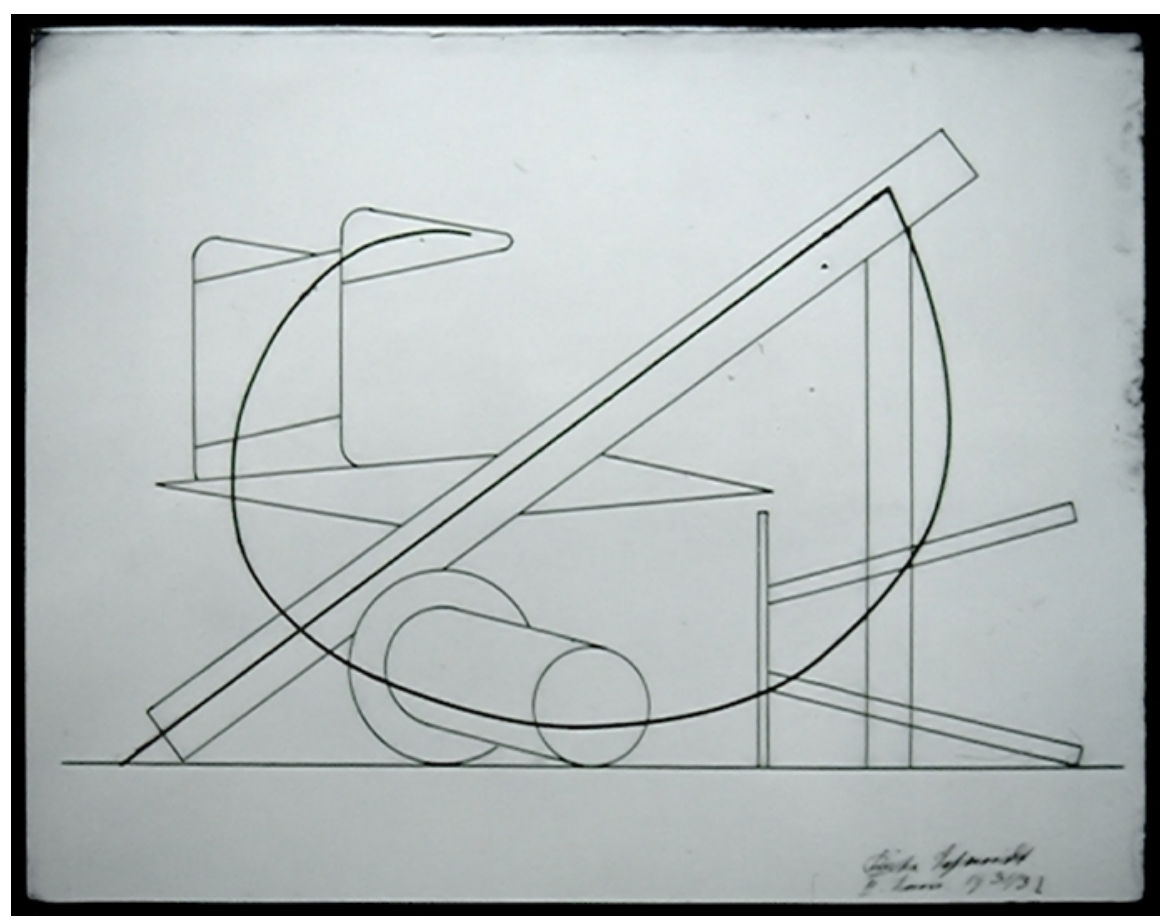

FIGURA 6.

Bauhaus-Archiv Berlin, Katja Rose, Analytische Zeichnung, medidas 24,3 x 52,5 cm. Realizado entre 1931/1932.

Así, la presencia de la geometría en los productos diseñados por la Bauhaus fue mucho más allá de su concepción general de la forma. La geometría estuvo presente tanto en productos realizados con técnicas clásicas, como la cerámica, así como en innovadores papeles pintados. Algunas de sus alumnas continuarían trabajando estos aspectos humanistas geométricos en cerámica tras su paso por la escuela. Este fue, de hecho, un aspecto imprescindible de la maravillosa producción de la ceramista Grete Marks (1899-1990) y sus vanguardistas diseños en los talleres Haël-Werkstätten fur künstlerische Keramik (véase Figura 7).

Recordemos que, de nuevo, este es un aspecto que compartieron con la plástica griega, con su decoración en cerámica, especialmente, a través de grecas y formas geométricas que se usaron como ornamentación con especial énfasis en el estilo protogeométrico y geométrico (s. IX y VIII a. C.), vinculado especialmente a zonas como Creta o Atenas. Este lenguaje se manifestó en la cultura primitiva griega con la llegada de las invasiones dorias: invasores nórdicos que "admiraban la técnica más que la decoración, la forma exacta y regular más que la elegancia. La precisión, acompañada de simplicidad, caracteriza todo lo que incluimos dentro del que llamamos estilo dórico" (Pijoán, 1996, p. 24). Es significativo el paralelismo esencial entre el lenguaje plástico geométrico fundamental de este pueblo (de origen nórdico, conquistador de aqueos y prehelénicos) y el lenguaje desarrollado en la Bauhaus. De hecho, esa espiritualidad a través de la forma simple que se trabajó en esta vanguardista escuela podría tener un sentir común con esta cultura antigua: "todo lo demás de la decoración son círculos, triángulos, recuadros y meandros que debían tener, sin embargo, un significado religioso" (Pijoán, 1996, p. 24). Son especialmente geométricas las piezas de Atenas que se consideran las más dorias de toda la cerámica griega de aquel momento. Es probable que, en aquella época primera de la cultura griega, esos vasos cerámicos fuesen el mayor soporte visual del momento, unas piezas célebres por su "excelente técnica, su elegancia de forma y su armonía entre forma y decoración" (Coldstream, 1977, p. 25). 


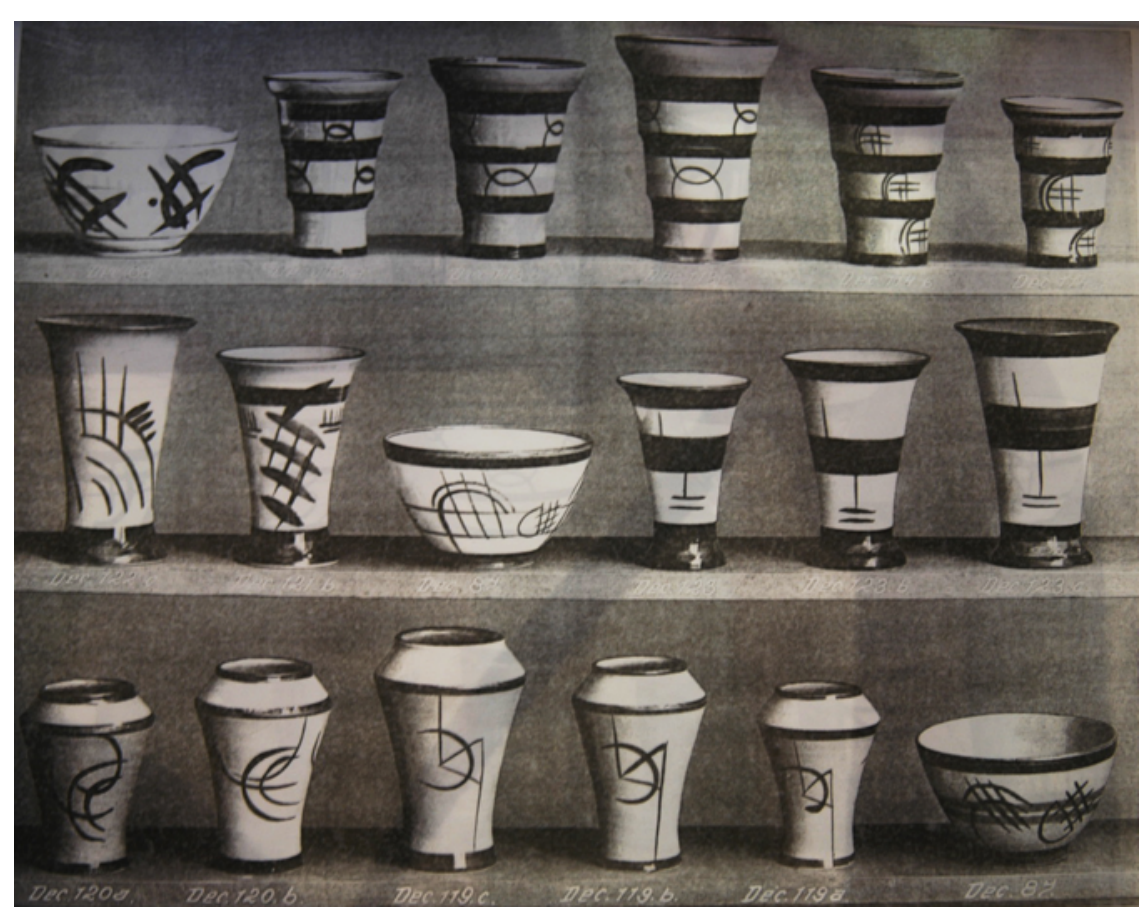

FIGURA 7.

Keramik Museum Berlin. Catálogo publicitario original de la marca Häel Werkstatten, 1924. Sin inventariar, cortesía del propietario, Heinz-Joachim Theis, director del museo.

Pero el recurso de la geometría no se quedó exclusivamente en el soporte del barro durante la primera sede de la escuela alemana en Weimar, sino que saltaría a las demás sedes de Dessau y Berlín a través de diversas disciplinas más técnicas. En el ámbito más asociado a las tecnologías del siglo XX, la geometría clásica estaría presente en la creación de productos innovadores como sus célebres papeles pintados o sus magníficos tejidos ya mencionados. Otro aspecto en el que se unieron geometría y tecnología sería en la producción propia de la sección de publicidad (diseños de carteles modernos), en fotografía (especialmente fotogramas abstractos y collages) o en la propia producción de mobiliario que hizo gala de una estética geométrica y una simplicidad de formas que le han valido en la actualidad el ser piezas aún celebradas, producidas y comercializadas.

De este modo, tenemos otras numerosas muestras de diseños en los que el conocimiento geométrico se manifestó, por ejemplo, en asignaturas como Tipografía, de la que se conservan magníficos apuntes al respecto de la alumna Monica Bella Ullman-Broner (1905-1993). Los cuales realizó en la clase de Joost Schmidt, siguiendo un modelo de retícula, a través de la que determinaban las formas tipográficas, tanto de caja alta como baja, de mayúsculas como minúsculas. En este sentido, también destacarían los innovadores diseños de juguetes o mobiliario infantil abstracto que realizó Alma Siedhoff-Buscher (1899-1944), resultado de una pasión por la simplicidad geométrica que intentaba dotar de libertad creativa a los niños y niñas durante el juego o el uso de su entorno, tal y como ella misma explicó en diversas publicaciones de la época como Junge Menschen (1925) o Vivos Voco. Zeischrift für neues Deutschtum (1926). En ellas, manifestaría algunas ideas como: "el niño y los cuentos = confusión por las ideas complejas, el niño y la fantasía = desarrollo y abundancia del pensamiento natural" (Siedhoff-Buscher, 1925, p. 189).

En general, la geometría estructural y formal se manifestaron en la Bauhaus como planteamientos compositivos imprescindibles para imponer el ideario visual, artístico y conceptual de sus productos. Es significativo que Matila Ghyka nos recordara, ya en la introducción de su célebre libro The geometry of art and life, la importancia de la geometría en las teorías de pensadores griegos como Platón, quien la consideraba imprescindible en el proceso por el que se materializa la obra de arte: 
Platón concebía al 'Demiurgo' (o ‘al que ordena como artífice’) como aquel que ordena el Cosmos armoniosamente según los arquetipos o ideas preexistentes, eternas, paradigmáticas, así que la visión platónica -o más bien neoplatónica- del arte concebía al artista como el que planifica su obra de arte según un sistema preexistente de proporciones, como una composición 'sinfónica', regida por una 'simetría dinámica' que corresponde en el espacio a la euritmia musical en el tiempo (Ghyka, 1946, p. ix).

Sin duda, la geometría, la composición o el conocimiento estructural de la obra de arte ha estado presente en la inmensa mayoría de producción plástica de nuestra historia. Sin embargo, dichos componentes de la obra plástica en ningún otro periodo como la época de la cultura clásica griega y de la Bauhaus han aflorado a la superficie con tanta belleza ni se manifestaron determinantes en la formalización de la misma. Consideramos que, en el caso de la Bauhaus, la geometría clásica -junto a los demás principios griegos mencionados- es un elemento esencial que le permitió incorporarse al lenguaje inédito de la vanguardia a través de sus diseños.

\section{CONCLUSIONES}

Por todo lo mencionado con anterioridad podríamos afirmar que la Bauhaus se acercó a lo real, a lo cotidiano, como ninguna otra escuela lo había hecho hasta entonces, de ahí que realizaran el camino contrario a Marcel Duchamp (1887-1968) quien incorporó un objeto industrial al ámbito artístico modificando la significación de lo plástico para siempre y estableciendo este último aspecto como algo imprescindible para la creación artística del siglo XX. La Bauhaus recorrió desde el arte -gracias a los ideales humanistas, a la geometría, la proporción y la armonía- el camino contrario, hacia lo cotidiano, a través de una 'physis' que fue geométrica, abstracta, basada en la armonía. Fue una máxima en la Bauhaus el entender la creación en este sentido, sus producciones fueron el resultado de una concepción compleja del ser humano, donde la geometría, proporción o armonía tenían una función en el objeto creado: la de darle forma, la de cumplir su función, la de manifestar su esencia y transmitir sus valores.

Así, los principios griegos aplicados al arte llegarían siglos más tarde, de un modo radical, a la vida cotidiana a través de su aplicación a los objetos y espacios que plantearía la Bauhaus. Los elementos fundamentales éticos, plásticos, de comunicación y concepción formal para la escuela alemana habrían sido propuestos, en esencia e inicialmente, por la cultura griega. En la Bauhaus fue imprescindible la relación de forma y función: res y verba (forma y contenido) humanista. Para estos profesores y estudiantes, la figura de referencia no era la elitista individualidad del genio renacentista, sino el ingenio humano al servicio de proyectos comunes. Así, esos conocimientos clásicos habrían pasado en el tiempo desde la cultura clásica griega a los objetos cotidianos de inicios del siglo XX a través de unos parámetros comunes, de una concepción espacial y de un desarrollo geométrico de la creación, convirtiéndose estos parámetros en la physis creativa de la escuela.

La Bauhaus funcionaría, por lo tanto, como un moderno oráculo de Delfos, prediciendo, desde su creación, el modo en el que diseñaríamos y viviríamos en occidente. La escuela tuvo su fin existencial en una pasión por lo moderno, pero esto fue el resultado de un concepto profundamente humanista de las artes y de la vida a través de las cuales desarrolló una pedagogía total que les llevó a pensar en el individuo como un todo, lo que definió su moderna identidad como escuela. Esta identidad moderna de la Bauhaus fue el resultado de una extensa tradición humanística europea cuyo origen lo situamos en la cultura griega antigua, en su concepción de physis, como una esencia activa que se manifestaría artísticamente en la escuela alemana de principios del siglo XX en tres aspectos fundamentales: la paideia, la armonía y la geometría. Gracias a ellos fueron vanguardia. Como consecuencia de la presente aproximación a los vínculos que unen la Grecia clásica con la Bauhaus, a través de su incipiente humanismo, podríamos considerar a su joven alumnado como 'dédalos' modernos y modernas; artesanos que se convirtieron en diseñadores acercándose, desde la arquitectura, a las necesidades de su propia época, un proceso en el que ellas, las alumnas, estuvieron igual de presentes que el resto de sus compañeros. 
Finalmente, entendemos que la Bauhaus fue una escuela antropocéntrica; de hecho, la consideramos la última manifestación académica humanista clásica de Europa. Prueba de ello es que pusieron el arte al servicio de la ética y del ser humano por encima del ego individual de la figura del artista. A pesar de la imagen aparente de frialdad racional que transmiten los objetos que se crearon en ella, estos son resultado de una perfecta conjugación de razón y emoción, vanguardia y clasicismo, de utilidad y estética, de arte y ciencia. La Bauhaus exploró la pedagogía transversal, como la formación total del ser humano humanista cuyo origen localizamos en la Antigua Grecia, como ciudadanos ideales. Se produjo, de este modo, una revolución artística y plástica en la que la aportación completa de su alumnado (el femenino incluido) resultó -además de multitudinariaimprescindible, como se puede comprobar en la producción textil, mobiliario o cerámica, al igual que en el compromiso social y plástico que pusieron en práctica los y las estudiantes durante sus respectivas carreras, a pesar de ser perseguidos y perseguidas por el nazismo.

\section{REFERENCIAS BIBLIOGRÁFICAS}

Albers, A. (1971). On Designing. Wesleyan University Press.

Aristóteles. (1994). Metafísica. Introducción, traducción y notas de Tomás Calvo Martínez. Editorial Gredos.

Berger, O. (s.f.). Gordijnstoffen D.P/ Carreaux [diseño de tejido]. Inv. № 3777. Bauhaus-Archiv Berlin/ Museum für Gestaltung.

Burckhardt, J. (2010). Historia de la cultura griega II. RBA Coleccionables.

Cabezas, L. (1995). El andamiaje de la representación. En J. J. Gómez (Coord.), Las lecciones del dibujo (pp. 217-339). Cátedra.

Calvo, T. (2000). La noción de Physis en los orígenes de la Filosofía Griega. Daimon Revista Internacional de Filosofía, (21), 21-38. https://revistas.um.es/daimon/article/view/11181/10771

Calvo, T. (2014). Notas para la conferencia Estética y matemáticas en el pensamiento griego. Manuscrito sin publicar.

Coldstream, J. N. (1977). Geometric Greece. Ernest Benn Limited.

Gropius, W. (1931). Zeugnis [certificado]. Inv. No 1956. Bauhaus-Archiv Berlin/ Museum für Gestaltung.

Eckermann, J. P. (2005). Conversaciones con Goethe. Acantilado.

Edgeston, S. (1975). The Renaissance Rediscovery of Linear Perspective. Basic Books.

Edlund, I. (1987). The Gods and the Place, Location and Function of Sanctuaries in the Countryside of Etruria and Magna Graecia (700-400 B.C). (Acta Instituti Romani Regni Sueciae, Series in $4^{\circ}$, 43.), p. 156 [archivo]. En The Classical Review (p. 414). Cambridge University Press. https:// doi:10.1017/S0009840X0027279X

Fehling, I. (1922). J.F: Figurinnen für die Marionetten bühne (Fotokopien) [boceto]. Carpeta 1, Inv. No 11813-2. Bauhaus-Archiv Berlin/ Museum für Gestaltung.

Flusser, V. (1999). Filosofía del diseño. La forma de las cosas. Editorial Síntesis.

García, J. M. (1991). El pensamiento científico en el humanismo renacentista: tradición y superación de los modelos greco-latinos. En J. A. Sánchez y M. López (Eds.), Humanismo renacentista y mundo clásico (pp. 107-131). Ediciones Clásicas.

Ghyka, M. (1927). Esthétique des proportions dans la nature et dans les arts. Librairie Gallimard.

Ghyka, M. (1946). The geometry of art and life. Sheed and Ward.

Goethe, J. W. (2020). La metamorfosis de las plantas. Atalanta.

Grunow, G. (1975). La construcción de la forma viva por medio del color, la forma, el sonido. En H. Wingler, $L a$ Bauhaus-Weimar, Dessau, Berlin 1919-1933 (pp. 279-280). Gustavo Gili.

Werkstatten, H. (1924). [Fotografía del catálogo publicitario original de la marca]. Keramik-Museum, Berlin.

Hervás y Heras, J. (2015). Las mujeres de la Bauhaus: de lo bidimensional al espacio total. Diseño Editorial.

Jaeger, W. (1957). Paideia: los ideales de la cultura griega. Fondo de Cultura Económica. 
Kandinsky, W. (2002). Escritos sobre arte y artistas. Editorial Síntesis.

Kirchmann, K. (2000). Oskar Schlemmer. En J. Fiedler y P. Feierabend. (Eds.), Bauhaus(pp. 280-292). Könemann.

Kirkham, P. y Weber, S. (2013). History of Design: Decorative Arts and Material Culture, 1400-2000. Yale University Press.

Krimmel, B. (1986). Symmetrie in Kunst, Natur und Wissenschaft, Band 1 y 2. Roetherdruck.

Kroll, F. (1987). Das Ornament in der Kunstheorie des 19 Jahrbunderts. Olms.

Leischner, M. (1968). The Bauhaus a legend? Journal of the Royal Society of Arts.

Lupton, E. y Abbott, J. (1993). The abc's of $5<=$ the Bauhaus and Design Theory. Thames and Hudson.

Makarova, E. (2001). Friedl Dicker-Brandeis Vienna 1898-Auschwitz 1944. Tallfellow.

Mauck, A. (s. f.). Entwurf für ein Wohnhaus in Berlin-Zeblendorf [archivo]. Carpeta 3, Inv. No 1997/26, 44-53. Bauhaus-Archiv Berlin/ Museum für Gestaltung.

Meyer-Bergner, L. (s. f.). Gewebe-Berechnung [manuscrito en archivo]. Inv. No I 15590. Stiftung Bauhaus Dessau.

Müller, U. (2009). Bauhaus Frauen: Meisterinnen in Kunst, Handwerk und Design. Elisabeth Sandmann Verlag.

Nauert, C. (1995). Humanism and the Culture of Renaissance Europe. Cambridge University Press.

Naylor, G. (1985). The Baubaus Reassessed. Sources and Design Theory. The Herbert Press.

Pijoán, J. (1996). Summa Artis. Historia General del Arte. Vol. 4: El Arte Griego hasta la toma de Corinto por los romanos (146 a.J.). Espasa Calpe.

Platón. (1987). Diálogos II. Editorial Gredos.

Rose, K. (1931-1932). Analytische Zeichnung, Bauhaus-Archiv Berlin/ Museum für Gestaltung.

Rössler, P. (2019). Bauhaus Mädels. A Tribute to Pioneering Women Artists. Taschen.

Satué, E. (1999). El diseño gráfico. Desde los origenes hasta nuestros días. Alianza Forma.

Schlemmer, T. (1970)....From the living Bauhaus and its stage. En E. Neumann (Ed.), Bauhaus and Baubaus People: Personal Opinions and Recollections of Former Bauhaus Members and Their Contemporaries (pp. 152-160). Reinhold.

Schuh, U. (1970). In Kandinsky's classroom. En E. Neumann (Ed.), Bauhaus and Bauhaus People: Personal Opinions and Recollections of Former Bauhaus Members and Their Contemporaries (pp. 160-163). Reinhold.

Siedhoff-Buscher, A. (1925). Kind-Märchen-Spiel-Spielzeug. Junge Menschen, 5(8).

Siedhoff-Buscher, A. (1926). Kindermöbel und kinderkleidung, Vivos Voco. Zeischrift für neues Deutschtum, 5(4).

Silson, E. (1994). 8000 Years of Ornament, an Illustrated Handbook of Motifs. The British Museum Press.

Torres, J. (1952). La recuperación del objeto (lecciones sobre plástica). Humanidades Digitales, (8), 5-255. http://hu manidades-digitales.fhuce.edu.uy/files/original/7ff097f9ce8876b9fe0af1328324a1d1.PDF

Vadillo, M. (2010). Otra mirada: las fotógrafas de la Bauhaus. Universidad de Córdoba y Universidad de Sevilla.

Vadillo, M. (2013). La Bauhaus y sus 'experimentos innecesarios': las arquitectas prófugas. Arte, individuo y sociedad, 25(3), 359-375. https://doi.org/10.5209/rev_ARIS.2013.v25.n3.39131

Vadillo, M. (2016). Las diseñadoras de la Bauhaus: historia de una revolución silenciosa. Cántico.

Vadillo, M. (2021). Las alumnas de la Bauhaus. Artes, oficios y revolución: las mujeres que marcaron la diferencia. Editorial Berenice.

Valéry, P. (1982). Eupalinos o el arquitecto. Colegio oficial de aparejadores y arquitectos técnicos de Madrid.

Valéry, P. (2004). La idea fija. Machado Libros.

Whitford, F. (1992). The Bauhaus. Masters \& Students by Themselves. Conran Octopus.

Wingler, H. M. (1975). La Bauhaus. Weimar, Dessau, Berlín. 1919-1933. Gustavo Gili. 


\section{Notas}

1 Una muestra puntual del interés internacional en la producción del alumnado femenino formado en la Bauhaus se manifiesta en que, durante la última década, se han publicado una serie de monografías y catalogaciones en inglés, alemán y francés rescatando sus figuras. Destacarían, entre las más recientes, coincidiendo además con el centenario de la fundación de la escuela en 2019, obras como la reedición de Ulrike Müller titulada Bauhaus Frauen: Meisterinnen in Kunst, Handwerk und Design, publicado por Elisabeth Sandmann Verlag. En este mismo año Patrick Rössler publicó Baubaus mädels. A tribute to pioneering women artists, editada por Taschen y Bauhaus women y A globalperspective junto a Elizabeth Rössler con la editorial Herbert Press. En español, destacan monografías recientes como las de la profesora de arquitectura Josenia Hervás y Heras titulada Las mujeres de la Baubaus. De lo bidimensional a lo tridimensional, publicado en 2016 por la Editorial Diseño de Buenos Aires. Esta visión, desde la arquitectura, se completa en castellano desde el ámbito de las Bellas Artes con los libros de la profesora Marisa Vadillo quien, en 2010, abordó la fotografía en Otra mirada: las fotógrafas de la Bauhaus, publicado por la Universidad de Sevilla; el diseño con Las diseñadoras de la Bauhaus: historia de una revolución silenciosa, en 2016, por la editorial Cántico y la situación general del alumnado femenino en todos los talleres con el libro Las alumnas de la Bauhaus. artes, oficios y revolución: Las mujeres que marcaron la diferencia, en 2021, con la editorial Berenice. La lista sería más extensa, pero, queremos señalar que esta selección de obras muestran la consolidación de una investigación que comenzó, tímidamente, a finales del siglo XX con investigaciones que se centraban en el Taller de Tejido y los diseños textiles de las alumnas. Una labor en la que figuras como Anja Baumhoff y Magdalena Droste fueron imprescindibles como pioneras en la recuperación de estas artistas.

2 Somos conscientes de la ingente cantidad de publicaciones que a lo largo de la historia han abordado la conexión entre belleza, matemáticas, arte y naturaleza. El listado de autores y autoras que han reflexionado sobre estos temas sería prácticamente interminable, tanto desde el punto de vista de la teoría artística como de la historia del arte o desde la estética. No obstante, consideramos que la aportación de Tomás Calvo, como uno de los especialistas en cultura griega de mayor prestigio internacional, tanto por su carácter inédito como por la especialización del investigador, es significativamente enriquecedora para nuestra investigación. 